\title{
The False S-curve Shaped by Licensing Agreements
}

\author{
Masamichi OGAMI $^{\text {a) }}$
}

\begin{abstract}
According to Foster (1986), technological progress naturally forms an S-curve. However, this study examines the progress of manufacturable sheet glass thickness using the float process and reveals that license agreements with grant-back clauses shape technological progress, indicated by an S-curve. More specifically, a competition for development was generated among licensees of the float process during the initial phase of licensing. Progress accelerated in the range of thicknesses in which plates could be manufactured. Nonetheless, at the end of license terms when parties are aware of expiring patents, research and development is suppressed due to grant-back clauses. This occurred because the parties attempted to outflank the competition after patents have expired. Thus, technological progress halts; however, this is a false S-curve that is not based on natural law. In fact, in the case of a float process, technological progress began once again after patents expired.
\end{abstract}

Keywords: S-curve, licensing, licensing community, float process, glass industry

a) Graduate School of Economics, Nagoya City University, 1 Yamanohata, Mizuho-cho, Mizuho-ku, Nagoya, Aichi, Japan, ogami@econ.nagoya-cu.ac.jp

An earlier version of this paper was presented at the ABAS Conference 2015 Summer (Ogami, 2015). 


\section{Introduction}

A technology S-curve is a function indicating the relation between the extent of effort and performance improvement (Foster, 1986). According to Foster (1986), technological progress is slow at the beginning due to lack of information required for developmental progress. As the requisite information is gathered, the rate of technological improvement increases. However, as the limit is reached, achieving technological progress becomes difficult. In other words, technological progress forms an S-curve, as illustrated in Figure 1.

However, this study suggests that licensing agreements may shape a technology S-curve.

When multiple companies use the same type of technology, each company will avoid an increase in patent licensing fees as a rational behavior and will instead initiate a competition for development by

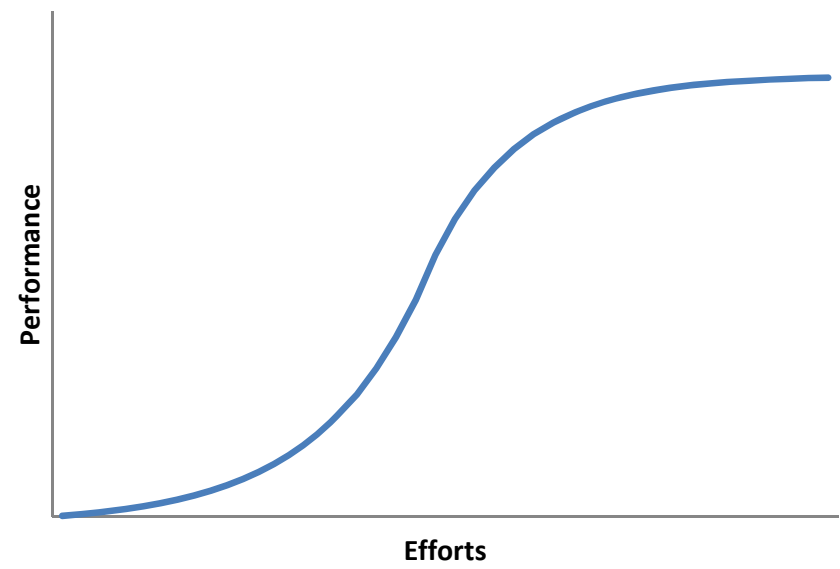

Figure 1. S-curve 
getting new patent fees. ${ }^{1}$ For example, when one licensor company licenses (patents) many licensees, a competition may emerge for development between licensees within the licensing community. ${ }^{2}$ This accelerates performance improvements for that technology.

However, grant-back clauses in licensing agreements eventually cause phenomena that apparently appear to be technological limitations. Grant back is the right given to a licensor during the term of an agreement to license a patent. It requires the licensees to give away the new patents, refinements, and knowhow licenses derived from original patent to the licensor (Wakumoto \& Nakano, 2005). This means that other licensees are given a license at some cost. Licensing communities formed around license agreements with these types of grant-back clauses have corporate behaviors in the initial stages of the license term that are no different than is described above. However, at the end of a license term, when there is a growing awareness of expiring patents, companies may suppress research and development in promising technologies and do not publicize or share the results of technology developments to outflank the competition (i.e., appropriate development results) by anticipating competition in the open development of technologies after patents expire. During such times, the rate of technological improvement decreases to form an S-curve, seemingly generating technological limitations. Indeed, this is a false S-curve that is not based on natural law.

This study uses the case of the evolution of the float

1 This paper's unit of analysis is the firm level; however, for differences in opinion between corporations and employees in regard to patents, see Takahashi (2014), and for the licensing business, refer Kishi and Takahashi (2010).

2 This study focuses on competitions over the same types of technologies; Christensen (1997) conducted a seminal research on competitions between technologies. Additional discussions on the study by Christensen include those by Danneels (2004), Takahashi, Shintaku, and Ohkawa (2013), Takamatsu and Tomita (2015), and Akiike and Iwao (2015). 
process_ currently the dominant technology used for forming plate glass - to examine the formation of an S-curve, about the "manufacturable thickness" of glass. The float process is a manufacturing technology for plate glass. This process was commercialized by Alastair Pilkington of the UK's Pilkington Glass Company in 1959. Glass manufactured using this process has a perfectly smooth glossy surface on both sides. Furthermore, considering the productivity and manufacturing costs, float process that does not require grinding and polishing can be produced much more efficiently given the productivity and manufacturing costs than with prior technologies, such as vertical or horizontal drawing process.

Pilkington Glass independently developed the float process to manufacture glass as thin as $3 \mathrm{~mm}$ and as thick as $6 \mathrm{~mm}$ until 1962, after which it began to license the technology to other companies worldwide, forming a licensing community. A development competition emerged within that community, which expanded the range of thicknesses at which plate glass could be formed. Eventually, however, the manufacturable thickness of plate glass halted when it reached a range of 2 to $19 \mathrm{~mm}$, with widths of approximately 2.5 to 4 meters. This manifested as an S-curve. At that point, the float process was unable to replace multiple other technologies.

However, immediate aftermath licensing to Japanese companies ended in 1981, the thickness at which plate glass could be formed began to increase once again. After licensing ended, the development on promising technologies that the company had suppressed to outflank the competition was later disclosed, and the results of technology developments were also accessible. Technological innovation that appeared to stop for a time as an S-curve then began advancing again. In other words, that was actually a false S-curve. When the Pilkington Glass patents expired, radical innovation began substituting for multiple existing technologies that 
had become compartmentalized, and the float process became the dominant technology in the first half of the 1980s.

This case indicates that prior to the expiration of patents, technology limitations not based on any natural law appear. In fact, discussions have been made on the role of patent system in suppressing technological innovation (Boldrin \& Levine, 2008). This can be seen in a famous example from England, which occurred after the expiration of Watt's steam engine patents (Boldrin \& Levine, 2008), as well as in Germany, where patents on the Otto cycle for automobiles were rendered invalid (Takahashi, 2013, chap. 2). In these cases, radical innovations made sudden leaps due to technologies being freed from patents or having the expectation of being freed from patents. These cases suggest policy implications for the industry.

\section{Technological Evolution of the Float Process ${ }^{3}$}

\section{Evolution of the float process}

The float process is a method for forming perfectly smooth sheet glass that is fire finished and parallel on both surfaces by pouring molten glass material over molten tin, which is heavier than glass and does not mix with it. This float process was developed for creating an alternative to the rollout process, which requires grinding and polishing for plate glass (Pilkington, 1969, 1970).

The range of thicknesses achievable in glass formed using the float process is primarily determined by the volume of molten glass poured

3 Description of glass forming technology is based on Asahi Glass Kabushikigaisya Rinji Shashi Hensanshitsu (1967, 2007), Moriya, Naruse, Kkunugi, and Tashiro (1963), Mori (2007), Naruse (1958), Nihonitagarasu Kabushikigaisya (1968), Ojima (1991), Ozeki (1981), Perry (1984), Pilkington (1969, 1970), Sakka, Sakaino, and Takahshi (1975), Wierzynski (1968), and Yamane et al. (1999). 
into the melting bath as well as the speed at which the glass ribbon is pulled from the melting bath into the annealing furnace by conveyance rollers. However, plate glass naturally formed at a thickness of $6.8 \mathrm{~mm}$ in the initial successes of float process development, and a thickness of $6 \mathrm{~mm}$ was achieved by slightly raising the speed. This $6-7 \mathrm{~mm}$ range is called an "equilibrium thickness." $50 \%$ of the market that was dominated by a rollout process of plate formation also had a thick glass of $6 \mathrm{~mm}$, causing Alastair Pilkington-the developer of the process-to recollect how circumstances favored him (Pilkington, 1969).

In forming a glass thinner than the equilibrium thickness, simply raising the speed at which the glass ribbon is pulled becomes problematic. A thickness of $5 \mathrm{~mm}$ is achievable with only a slight increase of roller speed over a $6 \mathrm{~mm}$ thickness. However, further increasing the roller speed to form plate glass thinner than $5 \mathrm{~mm}$ would be insufficient. This is because unnecessarily increasing the speed at which the glass ribbon is pulled narrows the width of the plate. For producing thin plate glass, a grooved top roller called auxiliary roller is used. This prevents the width of the glass ribbon from shrinking, with the auxiliary roller holding both ends of the glass ribbon that forms at equilibrium thickness on the molten tin.

Methods of manufacturing plate glass thicker than the equilibrium thickness are slightly simpler than processes for manufacturing thin glass sheets. Thick plate glass formed using the float process are produced by setting guides called carbon fenders at both the ends of a float bath filled with molten tin. These guides keep the glass from spreading to the sides, and the thickness of the glass ribbon is controlled by the speed and volume of the molten glass. Carbon fenders are sufficiently long to keep the glass at a lower temperature such that it does not spread under its own weight. 


\section{Formation of a float process licensing community}

Until 1962, Pilkington Glass independently developed the process that made forming plate glass of 3-6 $\mathrm{mm}$ thicknesses possible. Automotive manufacturers during that time used glass that was $3 \mathrm{~mm}$ thick. Beginning in 1962 when forming glass plates of 3 $\mathrm{mm}$ became possible, Pilkington Glass began to license its process to plate glass manufacturers throughout the world.

According to Wierzynski (1968), over a licensing term of 16 years, Pilkington disclosed all technological advances related to the float process to its licensees, and licensees of the Pilkington float process were in turn obligated to disclose their technological advances related to the float process. This is known as a "grant-back clause." Under these terms, any technological advances made by licensees, which were not patentable were disclosed by the licensees. However, patentable technologies were shared only between Pilkington Glass and the licensees who developed them. This clause did not preclude the sale of patentable technologies between licensees. These types of licensing agreements spurred a competition among companies that implemented the float process to develop technologies (Wierzynski, 1968).

\section{Greater range of manufacturable thickness through the float process}

In this manner, various basic processes and peripheral technologies were developed, and the range of manufacturable thicknesses of plate glass expanded. For plate glass thinner than $3 \mathrm{~mm}$, auto manufacturers-main customers of thin plate glass_-began adopting thinner plate glass of $2.5 \mathrm{~mm}$ in 1970 as a means of mass producing lighter, more fuel-efficient vehicles, moving to $2.3 \mathrm{~mm}$ glass in 1973, and $2 \mathrm{~mm}$ glass by 1978 (Mori, 2007).

On the other end of the spectrum, taller buildings caused Pilkington Glass and its licensees to compete for development of glass 
thicker than $8 \mathrm{~mm}$. Manufacturers produced products of $15 \mathrm{~mm}$ in 1966 and, at the outset of the 1970s, were able to use the float process to form plate glass of $19 \mathrm{~mm}$ in thickness. ${ }^{4}$ Plate glass thicker than $10 \mathrm{~mm}$ could not be formed using existing methods. Nippon Sheet Glass was successful in developing a method of producing glass of 15 and $19 \mathrm{~mm}$ and was the first in the world to bring them to market.

The comparison of the thicknesses formed using the rollout process and that using the float process can be summarized as follows. In the 1960s and 1970s, Plate glass thickness of 3-10 mm could be formed using the rollout process. In contrast, the float process could be used to form plate glass of up to $6 \mathrm{~mm}$ and as thin as $3 \mathrm{~mm}$ in the 1960s, though in the 1970s the float process enabled an upper limit of $15 \mathrm{~mm}$ and a lower limit of $2 \mathrm{~mm}$. Products of $2 \mathrm{~mm}$ thickness were primarily used in automobiles. By 1981, plate glass of more than $19 \mathrm{~mm}$ thickness could be formed using the float process, and these products were used in high-rise buildings. In other words, the float process was used to create both thicker and thinner plate glasses than those using the rollout process. Consequently, the rollout process was only used to manufacture special types of plate glass, such as wire mesh glass.

\section{Float process as an alternative to rollout process}

The float process was initially limited to the thicknesses it could produce. However, through the independent development efforts of Pilkington Glass and its subsequent licensing that spurred competitions for development, the range of thicknesses formable using the float process expanded and, in the end of the process, could handle all the thicknesses of the rollout process, becoming an

4 Manufacturers could form glass of $25 \mathrm{~mm}$ in the latter half of the 1970s. However, these products were not used as a plate glass but were used as a rib glass and thus are not mentioned in this paper. 
alternative method for forming polished plate glass. Excluding only certain cases, even sheet glass manufactured, a vertical or horizontal drawing process was replaced by the float process.

According to Perry (1984), when the float process was introduced in the US in 1963, approximately $51 \%$ of American plate glass production capacity was dedicated to sheet glass (using a vertical or horizontal drawing process), with the remaining $49 \%$ being polished plate glass (using the rollout process). In 1973-10 years after the implementation of the float process in the US- $59 \%$ of the plate glass production capacity in the US was undertaken by the float process, with $32 \%$ being sheet glass (using a vertical or horizontal drawing process) and approximately 9\% being polished plate glass (using the rollout process). Thus, the float process displaced not only the rollout process but also the vertical or horizontal drawing process.

However, the float process could not completely displace the vertical or horizontal drawing process. This was because refinements to that process were made primarily in Japan, and it reached a certain level of competitiveness with the float process. For example, Asahi Glass began the development of its original process called "Asahi-shiki" in 1967, which solved the fundamental problems of the Fourcault process in 1971. This original process was sufficiently competitive to become a technology export through the first part of the 1980s. Moreover, Nippon Sheet Glass used a Colburn process to manufacture ultrathin glass at a low cost in 1978, selling the products to the nascent LCD industry.

Consequently, a glass thinner than $2 \mathrm{~mm}$ continued to be produced using a vertical or horizontal drawing process as it could not be produced using the float process. Glass thinner than $2 \mathrm{~mm}$ is used in watches, calculators, touch screens, microscope slide cover glass, and thin-film solar cell substrates. In addition, specialty glass such as wire mesh glass cannot be formed using the float process 
and are till date produced using the rollout process.

\section{False limitations of float process technology}

From the 1960s to the 1970s, the float process could not completely displace the vertical or horizontal drawing process in the market for glass thinner than $2 \mathrm{~mm}$. This was due to an abundance of technological innovation on the vertical or horizontal drawing process compared with gradually less technological innovation occurring on the float process. At first glance, this is a technological S-curve.

A change in the speed of technological innovation on the float process manifests in the number of patent applications. Ozeki (1981) examines the change in Japanese float process-related patent applications; 5 Pilkington Glass and licensees produced approximately 20 patent applications in 1963, the year after licenses were given for the float process. The number increased to 50 in 1968 but declined to 15 in 1973, and with the end of license terms looming in 1978, the number declined to less than 10. This is an S-curve as development appeared to gradually decline as the end of the license term approached.

However, when the license relation between Asahi Glass and Pilkington Glass ended in 1981, Asahi Glass became successful in forming ultrathin glass of less than $2 \mathrm{~mm}$ using the float process. The company began mass production in 1982, which ended their use of the "Asahi-shiki" process. In 1989, Nippon Sheet Glass switched its method of manufacturing ultra-thin glass from the Colburn process to the float process. The switch in manufacturing processes by Nippon Sheet Glass came five years after Asahi Glass. The reason for this cannot be determined; perhaps, mass production of ultra-thin

5 Ozeki summarizes the number of patent applications by year for Pilkington Glass and each licensee, although the scale on the graph used is quite rough, with specific numbers not noted. 
glass was technologically difficult using the float method, or perhaps it was due to decision making of the Nippon Sheet Glass organization rather than any technological problem. ${ }^{6}$ It may have been both of these factors. Since then, the vertical or horizontal drawing process disappeared almost entirely.

In summary, the license relation between Asahi Glass and Pilkington Glass shaped the false limitation.

\section{Conclusion}

This study presents the case of the formation of an S-curve within a licensing community. Beginning in 1959, when the float process was commercialized, until 1962, when licensing of the float process to other companies began, Pilkington Glass independently worked on the development of the float process and manufactured glass with 3-6 mm thickness. After 1962, a competition for development within the licensing community enabled the manufacture of plate glass using the float process with thicknesses ranging 2-19 $\mathrm{mm}$, leading to the formation of an S-curve. However, after the end of license terms in 1981, Asahi Glass succeeded in forming ultrathin glass with thickness less than $2 \mathrm{~mm}$. In other words, the S-curve of technological progress seen during the licensing period was false, which merely reflected the license agreements and expectations for the agreement by each of the licensees.

This case suggests that as one considers the technological limitations in a licensing community, one must contemplate whether these are objective technological limitations based on natural laws, or

6 The switch in manufacturing processes by Nippon Sheet Glass came five years after Asahi Glass. The reason for this cannot be determined; perhaps, mass production of ultra-thin glass was technologically difficult using the float method, or perhaps it was due to decision making of the Nippon Sheet Glass organization rather than any technological problem. It may have been both of these factors. 
lulls in technological progress in anticipation of patent expirations, or in other words, false limitations. Some argue that the patent system inhibits technological innovation (Boldrin \& Levin, 2008), and industrial policy assuming that the patent system spurs technological development requires a serious discussion. However, no new technologies existed other than the float process in this case. In other words, when multiple competing technologies create their own licensing communities, a conclusion different than this may be reached. This suggests the need for further research.

\section{Acknowledgements}

This study was supported in part by the Global COE Program of Japan Society for the Promotion of Science for FY 2008-2009.

\section{References}

Akiike, A., \& Iwao, S. (2015). Criticisms on "the innovator's dilemma" being in a dilemma. Annals of Business Administrative Science, 14, 231-246. doi: 10.7880/abas.14.231

Asahi Garasu Kabushikigaisya Rinji Shashi Hensanshitsu. (Eds.). (1967). Shashi [Company history]. Tokyo, Japan: Asahi Glass (in Japanese).

Asahi Garasu Kabushikigaisya Rinji Shashi Hensanshitsu. (Eds.). (2007). Asahi garasu hyakunenn no ayumi [A century of Asahi Glass]. Tokyo, Japan: Asahi Glass (in Japanese).

Boldrin, M., \& Levine, D. K. (2008). Against intellectual monopoly. London, UK: Cambridge University Press.

Christensen, C. M. (1997). The innovator's dilemma: When new technologies cause great firms to fail. Boston, MA: Harvard Business School Press.

Danneels, E. (2004). Disruptive technology reconsidered: A critique and 
research agenda. Journal of Product Innovation Management, 21(4), 246-258.

Foster, R. N. (1986). Innovation: The attacker's advantage. London, UK: Macmillan.

Kishi, N., \& Takahashi, N. (2010). Licensing strategy of Japanese firms and competitive advantage. Annals of Business Administrative Science, 9, 1-12. doi: 10.7880/abas.9.1

Mori, T. (2007). Itagarasu seizou gijutsu no keitouka [Historical development of flat glass manufacturing technologies]. Kokuritsu Hakubutsukann Gijutsu no Keitouka Chousa Houkoku, 9, 121-164.

Moriya, T., Naruse, S., Kunugi, M., \& Tashiro, J. (Eds.). (1963). Garasu kougaku hanndobukku [Glass engineering handbook]. Tokyo, Japan: Asakurasyotenn (in Japanese).

Naruse, S. (1958). Garasu kougaku [Glass engineering]. Kyoritsusyuppann (in Japanese).

Nihonitagarasu Kabushikigaisya (1968). Nihonitagarasu Kabusikigaisya gojyuunennshi [50 years of Nippon Sheet Glass]. Osaka, Japan: Nippon Sheet Glass (in Japanese).

Ogami, M. (2015, August). False S-curve: The influence of licensing agreements. Paper presented at ABAS Conference 2015 Summer, University of Tokyo, Japan.

Ojima, M. (1991). Jidousyayougarasu no rekishi [History of automotive]. Jidousyagijutsukaikantoushibuhou Kousyou, 16, 11-16 (in Japanese).

Ozeki, K. (1981). Itagarasu no seikeihou: Furo-tohou to Asahishikihikiagehou [Glass forming: Float process and Asahi process]. Seramikkusu, 16(2), 118-121 (in Japanese).

Perry, R. C. (1984). The float glass process: A new method or an extension of previous ones? Glass Industry, 31, 17-19.

Pilkington, A. (1969). The float glass process. Proceedings of Royal Society of London Series A, 314, 1-25.

Pilkington, A. (1970). The float process. Journal of the Institute of Fuel, 43(354), 252-254.

Sakka, S., Sakaino, T., \& Takahashi, K. (Eds.). (1975). Garasu hanndobukku [Glass handbook]. Tokyo, Japan: Asakurasyotenn (in 
Japanese).

Takahashi, N. (2013). Kara: Datsu jirihinn no keiei [Shell: Out from under dwindling of business]. Kyoto, Japan: Minervashobo (in Japanese).

Takahashi, N. (2014). Four side views of blue LED patent pricing. Annals of Business Administrative Science, 13, 299-313. doi: 10.7880/abas. 13.299

Takahashi, N., Shintaku, J., \& Ohkawa, H. (2013). Is technological trajectory disruptive? Annals of Business Administrative Science, 12, 1-12. doi: 10.7880/abas.12.1

Takamatsu, T., \& Tomita, J. (2015). Disruptive innovation: A case of full mold casting. Annals of Business Administrative Science, 14, 109-126. doi: 10.7880/abas.14.109

Wakumoto, Y., \& Nakano, K. (2005). Keiei senryaku toshiteno raisensu [License as management strategy]. Akamon Management Review, 4, 1-44. (in Japanese).

Wierzynski, G. H. (1968). The eccentric lords of float glass. Fortune, (1968, July), 90-92, 121-124.

Yamane, M., Yasui, I., Wada, M., Kokubu, Y., Terai, R., . . . Ogawa, S. (Eds.). (1999). Garasu kougaku hanndobukku [Glass engineering handbook]. Tokyo, Japan: Asakurasyotenn (in Japanese). 